JOURNAL DE PHYSIQUE IV

Colloque C8, supplément au Journal de Physique III, Volume 6, décembre 1996

\title{
Structural Relaxation in Amorphous Alloys of Type FeSiB
}

\author{
G. Haneczok, J. Rasek, Z. Stoklosa and B. Zegrodnik \\ Institut of Physics and Chemistry of Metals, Silesian University, 40-007 Katowice, Poland
}

\begin{abstract}
The Irreversible component of the structural relaxation in two ferromagnetic amorphous alloys $\mathrm{Fe}_{78} \mathrm{Si}_{9} \mathrm{~B}_{13}$ and $\mathrm{Fe}_{78} \mathrm{Si}_{13} \mathrm{~B}_{9}$ was examined by making use of mechanical spectroscopy and isothermal time instability measurements of shear modulus $G(t)$ and magnetic permeability $\mu(t)$. It was shown that the first stage of the structural relaxation, attributed to the rearrangements of anisotropic atom pairs $\mathrm{Si} / \mathrm{B}$ in the vicinity of free volumes takes place in the temperature range $300-500 \mathrm{~K}$ with the mean activation energy $\mathrm{E}=0.9 \mathrm{eV}$ (the spectrum stretches between $0.6-1.2 \mathrm{eV}$ ). The second stage - annealing out of free volumes - takes place in the temperature range $500-700 \mathrm{~K}$ with $\mathrm{E}=1.4 \mathrm{eV}$ (the spectrum stretches between $1.2-1.7 \mathrm{eV}$ ).
\end{abstract}

\section{INTRODUCTION}

Amorphous ferromagnetic alloys obtained from the liquid phase by rapid cooling exhibit very good magnetic and electric properties [1-4]. As a consequence of the fact that these materials are not in a thermodynamic equilibrium state their properties exhibit high instability with respect both to time and temperature e.g. $[5,6]$. The process of achieving the thermodynamic equilibrium state take place by means of structural relaxation and crystallisation. Both phenomena are controlled by low temperature diffusion, hence to study them it is necessary to make use of nonconventional techniques such as: mechanical spectroscopy, electrical conductivity or magnetic properties measurements (e.g. permeability relaxation). In many papers (e.g. [7-20]) it was already demonstrated that such physical magnitudes as Young/shear modulus, magnetic permeability or electrical conductivity are very sensitive to small changes in the microstructure of the examined materials.

In general there are two components of structural relaxation - a reversible and an irreversible. The experimental study of both components allows to obtain information about the atomic movements attributed to the processes of achieving the thermodynamic equilibrium state. This information is also important from the practical point of view because the high instability of amorphous alloys hinders their application. The aim of the present paper is to study the irreversible component of the structural relaxation in two ferromagnetic amorphous alloys $\mathrm{Fe}_{78} \mathrm{Si}_{9} \mathrm{~B}_{13}$ and $\mathrm{Fe}_{78} \mathrm{Si}_{13} \mathrm{~B}_{9}$ by making use of mechanical spectroscopy and isothermal time instability measurements of shear modulus $G(t)$ and magnetic permeability $\mu(t)$.

\section{EXPERIMENTAL RESULTS}

The experiments were carried out on two amorphous ferromagnetic alloys $\mathrm{Fe}_{78} \mathrm{Si}_{9} \mathrm{~B}_{13}$ and $\mathrm{Fe}_{78} \mathrm{Si}_{13} \mathrm{~B}_{9}$ obtained from the liquid phase by rapid cooling in the form of strips of thickness of about 20-30 $\mu \mathrm{m}$ and $10 \mathrm{~mm}$ width. Magnetic permeability $\mu$ of samples about $9 \mathrm{~cm}$ long, in a magnetic circuit closed with a permalloy keeper, were determined by applying the Maxwell-Wien bridge equipped with a selective zero indicator and a demagnetisation system. The measurements were made in a weak magnetic field $0.6 \mathrm{~A} / \mathrm{m}$ of frequency $1030 \mathrm{~Hz}$ with and without demagnetisation. For mechanical spectroscopy measurements the samples of the width of about $5 \mathrm{~mm}$ and the length of $5 \mathrm{~cm}$ were used. The mechanical loss spectra $Q^{-1}(T)$ were measured in the temperature range $300-900 \mathrm{~K}$ (free vibration with the frequency $f=1-0.5 \mathrm{~Hz}$ ) with the heating rate $v_{\mathrm{g}} \approx 2-2.5 \mathrm{~K} / \mathrm{min}$. The maximum of $Q^{-1}(T)$ observed at $730-770 \mathrm{~K}$ (for different $v_{\mathrm{g}}$ ) was attributed to the crystallisation process. 
In order to study the irreversible component of structural relaxation the isothermal changes of dynamic shear modulus $G(t)$ and magnetic reluctivity $r(t)$ (without demagnetisation) were measured as a function of time $t(r=1 /(\mu-1)$ is proportional to defects concentration). For $G(t)$ measurements the following procedure was used: 1 the sample in the state "as quenched" was fixed in the pendulum and the frequency of the vibration $f\left(G \propto f^{2}\right)$ was measured as a function of time at constant, sufficiently low temperature until the observed changes were negligible, 2 . the annealing temperature was increased with the heating rate of about $30 \mathrm{~K} / \mathrm{min}$ and again at higher temperature the curve $f^{2}(t)$ was recorded. Fig. 1 presents five isothermal curves $f^{2}(t)$ obtained for the alloy $\mathrm{Fe}_{78} \mathrm{Si}_{9} \mathrm{~B}_{13}$. It is proper to add that no significant time-related changes were observed on the $G(t)$ curves up to the temperature $450 \mathrm{~K}$.

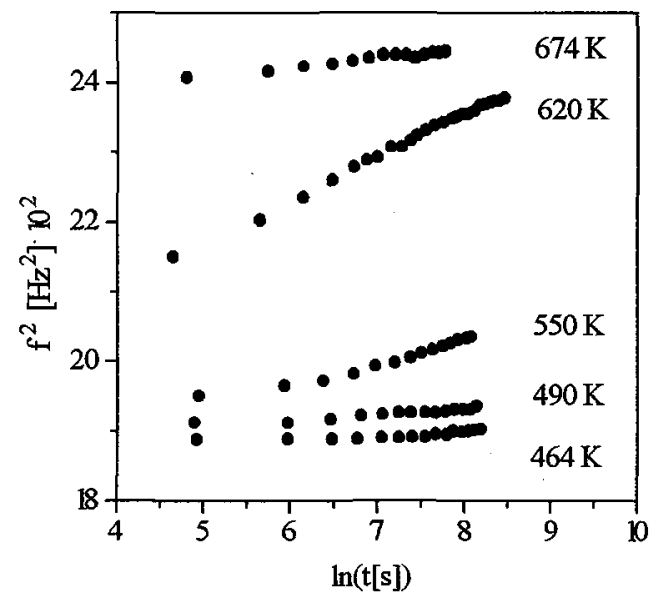

Fig.1 Isothermal curves $\mathrm{f}^{2}(\mathrm{t})$ obtained for $\mathrm{Fe}_{78} \mathrm{Si}_{9} \mathrm{~B}_{13}$

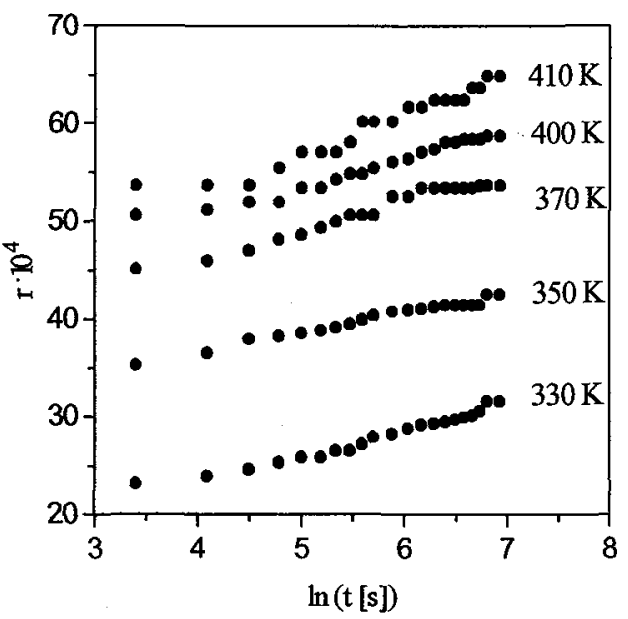

Fig.2 Normalised isothermal curves $\Delta \mathbf{r} / \mathrm{r}$ for $\mathrm{Fe}_{78} \mathrm{Si}_{9} \mathbf{B}_{13}$ (without demagnetisation)

The isothermal measurements of magnetic reluctivity $r(t)$ were carried out in the temperature range 300$500 \mathrm{~K}$. The essential idea of the experiments was the same as in the case of $G(t)$. Fig. 2 shows a family of isothermal curves $r(t)$ obtained for $\mathrm{Fe}_{78} \mathrm{Si}_{9} \mathrm{~B}_{13}$ alloy. Similar results as presented in Fig.1,2 were obtained for $\mathrm{Fe}_{78} \mathrm{Si}_{13} \mathrm{~B}_{9}$ alloy.

\section{IRREVERSIBLE COMPONENT OF THE STRUCTURAL RELAXATION}

The process of the structural relaxation may be related to an energy spectrum $p(E, t)$ responsable for the kinetics of a certain physical quantity $F(t)$ sensitive to structural changes [6,22-26]. According to the approach proposed by Primak [22-26] it may be written as:

$$
F(t)=\int_{0}^{\infty}\left[p_{0}(E)-p(E, t)\right] d E
$$

where $p_{0}(E)$ denotes the energy spectrum characterising the sample in the "as quenched" state, $E$ is the activation energy of atom jumps from/to positions separated by a potential barrier, $p(E, t)$ denotes the energy spectrum that varies with time due to the materials approach to thermodynamic equilibrium. In the first approximation these changes may be described by the equation of type:

$$
\frac{d p}{d t}=-\frac{p}{\tau}
$$


where the relaxation time $\tau$ obeys the Arrhenius relation

$$
\tau=\tau_{\infty} \exp (E / k T)
$$

in which $\tau_{\infty}$ is the preexponential factor and $\mathrm{k}$ is the Boltzmann constant. From eqs.(1-3) the following expression may be obtained [6,22-24]:

$$
\frac{d F(t)}{d \ln \left(t / \tau_{\infty}\right)}=k T p_{0}\left[E=k T \ln \left(t / \tau_{\infty}\right)\right]
$$

where $p_{0}$ is the value of function $p_{0}(E)$ at the point $E=k T \ln \left(t / \tau_{\infty}\right)$. Equation (4) allows to determine the spectrum of activation energies $p_{0}(E)$ associated with the relaxation effect by measurements of the time relations $F(t)$ performed at a constant temperature $T$. The slope of the straight line $F(t)$ versus $\ln (t)$ determines the value $p_{0}$ for the energy interval $\Delta E=k T\left[\ln t_{2}-\ln t_{1}\right.$, , where $t_{2}-t_{1}$ denotes the time interval for which $F(t)$ is linear in the logarithmic scale.

The results of the analysis of isothermal measurements (Fig.1 and 2) made by applying eq.(4) are presented in Fig. $3 \mathrm{a}$ and $3 \mathrm{~b}$ for shear modulus $\left(F(t)=f^{2}(t)\right)$ and magnetic reluctivity $(F(t)=r(t))$, respectively. In the calculations it was assumed that the value of the preexponential factor $\tau_{\mathrm{c}}$ is $10^{-9} \mathrm{~s}$, as it was determined in $[25,26]$ for a multicomponent amorphous $\mathrm{Fe}_{32} \mathrm{Ni}_{36} \mathrm{C}_{14} \mathrm{P}_{12} \mathrm{~B}_{6}$ alloy. It is important to emphasise that $\tau_{\mathrm{os}}$ establishes only the energy axis of the examined spectrum; $a$ change of its value even by an order of magnitude merely causes a slight shift of the whole spectrum by about $\pm 0.05 \mathrm{eV}$.

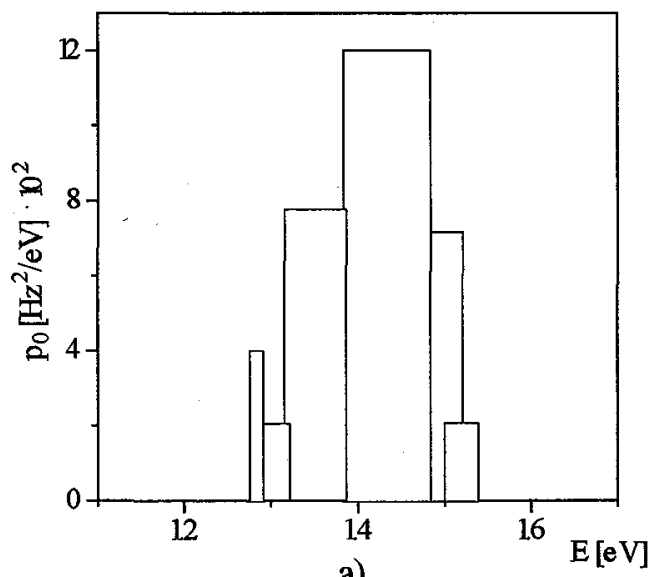

a)

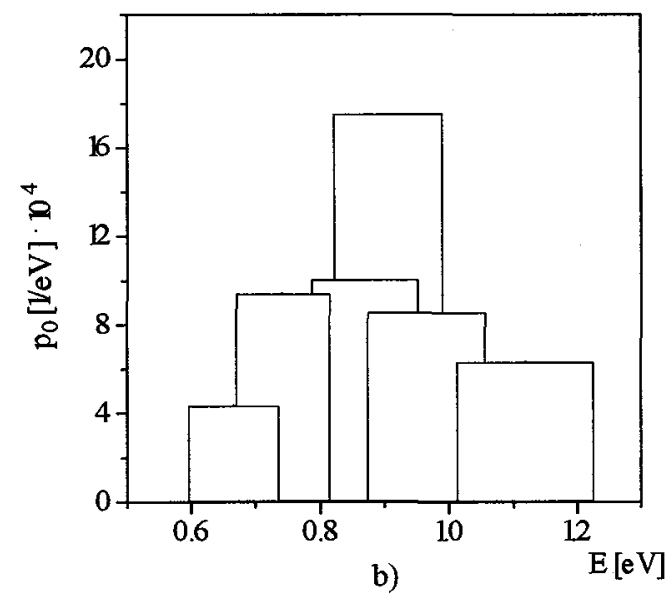

b)

Fig. 3 The activation energy spectrum obtained for amorphous alloy $\mathrm{Fe}_{78} \mathrm{Si}_{9} \mathrm{~B}_{13}$ by making use of isothermal measurements a) shear modulus (temperature range $450-700 \mathrm{~K}$ ) and b) magnetic reluctivity (temperature range $300-500 \mathrm{~K}$ )

\section{DISCUSSION AND CONCLUSIONS}

The results of the analysis presented in the previous section show that the spectrum of activation energies responsible for the irreversible changes of magnetic permeability in $\mathrm{Fe}_{78} \mathrm{Si}_{9} \mathrm{~B}_{13}$ alloy stretches in the interval $0.6-1.2 \mathrm{eV}$ with the most probable value of $0.9 \mathrm{eV}$ (Fig.3b). As the first stage of structural relaxation this process can be attributed to the rearrangements of anisotropic atom pairs $\mathrm{Si} / \mathrm{B}$ in the vicinity of free volumes [11,12]. According to the so-called two levels model [16] atom jumps between two energy levels separated by a relatively large asymmetric potential barrier lead to irreversible structural changes. Greater clusters of microvoids are formed due to this process. The results of measurements presented in Fig. 1 for shear modulus and in Fig. 2 for magnetic permeability show also that the shear modulus is not a sufficiently sensitive magnitude to permit the study of microstructural changes 
associated with the rearrangements of anisotropic atom pairs, which are recorded by changes in magnetic permeability at temperatures $300-500 \mathrm{~K}$.

The second stage of structural relaxation takes place at higher temperatures and can be observed as isothermal changes of shear modulus (Fig.1). The spectrum of activation energies responsible for this process stretches in the energy interval 1.1-1.7 eV with the most probable value of $1.4 \mathrm{eV}$ (Fig.3a). This microstructural changes may be associated with the migration and disappearance (annealing out) of the free volumes frozen-in during the production process. The annealing of free volumes leads to the formation of nanocrystaline phase in the amorphous state. As it was shown in [21] by making use of electron microscope examination for similar amorphous alloy $\left(\mathrm{Fe}_{78} \mathrm{Si}_{8} \mathrm{~B}_{14}\right)$ the nanocrystaline phase is already present in the tested samples after the annealing at $698 \mathrm{~K} / 1 \mathrm{~h}$. This phase is responsible for the observed increase of the initial magnetic permeability (annealing at temperatures $550-650 \mathrm{~K} / 1 \mathrm{~h}$ causes an increase of $\mu$ about 5-times [21]). According to the random anisotropy model [3,5,27] the magnetic permeability strongly increases if the dimension of crystallites are smaller than the length of the exchange interaction.

The main conclusions from the analysis of isothermal measurements presented in this paper are the following: i) the first stage of the irreversible structural relaxation in FeSiB amorphous alloys take place in the temperature range $300-500 \mathrm{~K}$ and is attributed to the rearrangements of anisotropic atom pairs $\mathrm{Si} / \mathrm{B}$ in the vicinity of free volumes with the mean activation energy $-0.9 \mathrm{eV}$, ii) the second stage is associated with the annealing of free volumes and take place in the temperature range 500-700 $\mathrm{K}$ with the mean activation energy $1.4 \mathrm{eV}$.

\section{Acknowledgements}

This work was supported by the Polish State Committee for Scientific Research (grant No.7T008 04408).

\section{References:}

[1] H.Kronmüller, J.Magn.Mater., 140-144 (1995) 25-28.

[2] K.Pękala, P.Jaśkiewicz, T.Kulik, Nonstructured Mater.,4 (1994) 707-721.

[3] X.Q.Li,X.L.Yang, B.Y.Hu,Z.Wu, Y.Z. Zhang, H.J.Jin, G.Q.Xu, J.Magn.Magn.Mater.,145 (1995) 125-128.

[4] J.M.Barandiaran, L,F. Barguin, J.C.G. Sal, P.Gorria, A.Hernando, Sol. State Comm.,88 (1993) 75-80.

[5] R.Grössinger, S.Turtelli, IEEE Transactions on Magnetics 30 (1994) 455-460.

[6] B.Zegrodnik, G.Haneczok, J.Rasek, Material Science Archives 15 (1994) 161-175.

[7] M.Kameda, H.Mijajima, J.Magn.Magn.Mater.,104-107(1992) 1115-1121.

[8] P.Alia, C.Beatrice, G.Brida, F.Vinai, J.Magn.Magn.Mater.,101(1991) 49-56.

[9] J.W.Moroń, Proceedings of the 9-th International Conference on Internal Friction and Ultrasonic Attenuation in Solids, Inter. Acad. Publ., Beijing and Pergamon Press, Oxford 1990, p.269-273.

[10] G.Riontino, G.W.Koebrugge, M.Baricco, J.Sietsma, Phys.Stat.Sol (b), 179 (1993) 315-321.

[11] J.Rivas, M.A.Lopez-Quintela, D.Martinez, F.Waltz, H.Kronmüller, J.Non-Cryst.Sol.,131-133 (1991) 1235-1239.

[12] F. Waltz, H.Kronmüller, D.Martinez, J.Rivas, Phys.Stat.Sol (a), 138 (1993) 265-279.

[13] G.A.Stergioudis, J.Yankinthos, P.J.Rentzeperis, Z.Bojarski, T.Panek, J. Mater.Sci., 27 (1992) 2468-2472.

[14] Z.Kaczkowski, L.Małkiński, M.Müller, IEEE Transaction on Magnetics,31(1995) 791-794.

[15] W.Ciurzyńska, J.Zbroszczyk,J. Magn. Magn. Mater., 140-144 (1995) 447-448.

[16] H.Kronmüller, Phil.Mag.,B48 (1983) 127-150.

[17] F.Rettenmeier, E.Kisdi-Koszo, H.Kronmüller, Phys.Stat.Sol.(a) 93 (1986) 597-604.

[18] F. Rettenmeier, H.Kronmüller, Phys.Stat.Sol.(a) 93 (1986) 221-231.

[19] M.Foldeaki, L.Koszegi, R.A.Dunlap, Phil.Mag., B48 (1991) 1101-1117.

[20] J.Philibert, Atom Movements, Diffusion and Transport in Solids, Monographies de Physique, Paris 1991, p.382-386.

[21] Z.Stokłosa, P.Kwapuliński, J.Rasek, J.Ilczuk, J.Lelątko, Acta Phys. Polon. A, 89 (1996) 437-442.

[22] W.Primak, Phys. Rev., 100 (1955) 1677-1689.

[23] M.R.J.Gibbs, D.W.Stephens, E.J.Evetts, J.Non-Cryst.Sol.,62 (1984) 925-930.

[24] G.Hugate, M.R.J.Gibbs, J.Phys.F: Metal.Phys.,17(1987) 815-826.

[25] K.Bothe, H.Neuhäuser, J.Non-Cryst.Sol.,56(1989) 279-284.

[26] K.Bothe, H.Neuhäuser, Scripta Met.,16 (1982) 1053-1057.

[27] B.Herzer, IEEE Transactions on Magnetics, 25 (1989) 3327-3329. 